\title{
Evaluating geovisualization for spatial learning analytics
}

\author{
Anthony C. Robinson (1D) ${ }^{a}$, Cary L. Anderson (D) ${ }^{b}$ and Sterling D. Quinn (1D ${ }^{c}$ \\ ${ }^{a} G e o V I S T A$ Center, Department of Geography, The Pennsylvania State University, University Park, PA, USA; \\ bJoseph M. Katz Graduate School of Business, University of Pittsburgh, Pittsburgh, PA, USA; 'Department of \\ Geography, Central Washington University, Ellensburg, WA, USA
}

\begin{abstract}
Contemporary systems for supporting digital learning are capable of collecting a wide range of data on learner behaviours. The emerging science and technology of learning analytics seeks to use this information to improve learning outcomes and support institutional assessment. In this work we explore the potential for the spatial dimension in learning analytics, and we evaluate a prototype geovisualization system designed to support what we call spatial learning analytics. A user evaluation with geographers and educators was conducted to characterize the usability and utility of our prototype spatial learning analytics system. By helping us understand what our prototype system does and does not do well, we are able to suggest a variety of new ways in which future spatial learning analytics systems can be developed.

RÉSUMÉ

Les systèmes actuels utilisés pour faciliter l'apprentissage numérique sont capables de collecter un très grand nombre de données sur le comportement des apprenants. Les sciences et techniques émergentes en analyse de l'apprentissage cherchent à utiliser ces informations pour améliorer les résultats d'apprentissage et pour aider l'évaluation institutionnelle. Dans ce travail nous explorons le potentiel de la dimension spatiale dans l'analyse de l'apprentissage et nous évaluons un prototype de système de géovisualisation conçu pour faciliter ce que nous appelons l'analyse spatiale d'apprentissage Une évaluation des utilisateurs par des géographes et des éducateurs a été menée pour caractériser l'utilisabilité et l'utilité de notre prototype de système d'analyse spatial d'apprentissage. En nous aidant à comprendre ce que notre système fait correctement et ce qu'il ne fait pas correctement, nous sommes capable de proposer une variété de nouvelles façons qui pourront être intégrées dans le développement de futurs systèmes d'analyse spatial d'apprentissage.
\end{abstract}

\section{ARTICLE HISTORY}

Received 5 September 2019

Accepted 23 February 2020

\section{KEYWORDS}

Geovisualization; learning analytics; user evaluation

\section{Introduction}

Understanding the roles of geography in learner engagement can help educators develop high quality courses and global learning experiences that account for geographic 
differences and leverage them to support improved learning outcomes. Our work connects closely to recent calls for the development of the spatially-enabled smart campus (Janelle, Kuhn, Gould, \& Lovegreen, 2014; Skupin, 2013), a vision for a flexible learning environment that includes location technology and science at its core to support learners working together as well as new forms of educational content that adapt automatically to different scales and places of focus. In order to achieve the vision of a spatially-enabled campus, we must first understand the situations in which geography matters in terms of modifying modes of educational engagement and influencing improved in outcomes. Our work to design and evaluate MapSieve, a geovisual analytics system designed to support spatial learning analytics, represents progress toward addressing this gap in our scientific knowledge.

Current learning analytics approaches provide insights on assessment performance and student interactions, but do not shed light on the roles that geography may play. Therefore, this project seeks to answer the question: How can geographic information help us characterize, explain, and improve learning in online courses? We hypothesize that leveraging geographic information in conjunction with traditional learner engagement metrics in what we call spatial learning analytics systems can (1) help instructors improve the quality of their teaching, (2) help students connect with each other and their instructors, and (3) support the analytical goals of those who work on institutional assessment.

In this article we introduce and evaluate a geovisualization system for supporting spatial learning analytics. This system includes coordinated spatial and attribute visualizations that are coupled with a computational method for enhancing the utility of faceted search in geographic visualization by pre-computing to uncover which combinations of learner behaviour attributes (e.g. forum posts, grades on quizzes, etc ...) (A) have results at all to visualize, and (B) which of those combinations include significant spatial hotspots. We implement this approach in a geovisual analytics system we call MapSieve which is designed to support analysis of learner activity data from a Massive Open Online Course (MOOC). Through a user evaluation we show how geovisualization can reveal interesting combinations that analysts can use to understand learner behaviours and to make judgments about pedagogical effectiveness. We conclude with ideas for further extension of cartographic and spatial analysis approaches to learning analytics and highlight its potential strengths and weaknesses vis-à-vis the new realities associated with big spatial data, new sources of learner data, and supporting the development of spatiallyenabled campuses.

\section{Background}

\section{Learning analytics}

The emerging science of learning analytics has been theorized in many ways, but the most commonly applied model is the five-step process proposed by Campbell, DeBlois, and Oblinger (2007). Their model consists of five stages: capture, report, predict, act, and refine. Subsequent developments in this domain have defined learning analytics as the '... measurement, collection, analysis, and reporting of data about learners and their contexts, for purposes of understanding and optimizing learning and the environments in 
which it occurs' (Siemens \& Baker, 2012). Researchers in the computational and social sciences have blended concepts from learning analytics into the co-emergent fields of educational data mining (Romero \& Ventura, 2007) and social learning analytics, respectively (Shum \& Ferguson, 2012).

Current platforms for learning analytics include a wide range of commercial systems that are part of or can be plugged into a contemporary Learning Management System (LMS). Such solutions can focus on a variety of analytical needs; for example, Hobson's Starfish is designed to support student advising and retention, while Civitas' Illume and Inspire systems focus on institutional assessment and improving individual class experiences respectively.

The development of MOOCs has also helped to inspire new forms of learning analytics systems. Beginning in the early 2010s, the Massive Open Online Course model of distance learning rose to popular prominence via MOOC platforms like Coursera, edX, and Udacity. Major universities around the world participated in launching courses via these platforms, and considerable media attention was placed on the potential for free online courses to reach massive new audiences. In subsequent years, MOOC platforms have sought to profit from their learner populations and the presence of features that support massiveness and openness has waned. Recent work by (Bennett \& Kent, 2017) characterizes the rise and evolution of MOOCs over time, and (Adams, 2018) explores and critiques the evolution of Geography MOOCs more specifically.

Whether or not we are indeed in a post-MOOC or at least beyond the peak-MOOC era, the challenges associated with effectively teaching students at a massive scale in MOOCs has prompted the need for new analytical methods that can help instructors identify key trends among their student cohorts when it is functionally impossible for every single student to be individually evaluated. MOOC data include website logs of video and content interactions, contributed assessment scores and assignments, as well as forum discussions. For example, Chen et al. (2015) have shown how a visual analytics approach can be applied to identify and characterize peaks in MOOC student activity as indicated by lecture video interaction logs. Their PeakVizor system grounds these peaks in activity by linking them with flowlines to a world map which aggregates student activities to a country level. Their efforts hint at what may be possible by better leveraging the geographic components of learner activity, showing that even the simple connection between where students are located and what parts of lecture videos they watch has the power to help instructors understand how different parts of a massive global cohort are engaging with the course content. Related work by Wu, Yao, Duan, Fan, and Qu (2016) to explore the social connections among MOOC students has also included a locational component (again at the country level) to highlight the development of study groups and to characterize their interconnections. Much more remains to be known about the potential utility of geographic information in learning analytics - these examples along with the research progress we share in this article suggest that this component deserves more attention than it has received to date.

The prevalence of learner activity data is increasing rapidly as universities and colleges around the world adopt new digital learning management systems that can easily collect and produce these data. According to the United States Department of Education (2014), the proportion of students taking fully online courses is growing every year, currently comprising $13 \%$ of all enrolments in U.S. higher education, and more than $26 \%$ of students take 
blended online/resident courses. Extrapolated to a global context, it is clear that millions of learners are already working within learning management systems. In both online and blended courses student location information can be more difficult for educators to characterize and assess compared to what can be assumed and witnessed directly in an on-campus course.

In this research we seek to align the goals of learning analytics with those of visual analytics, and specifically focus on the potential for geovisual analytics as a new lens through which learning can be characterized and understood using spatially-referenced learner activity data. Visual analytics is the science of analytical reasoning as facilitated by interactive visual interfaces (Thomas \& Cook, 2005), and geovisual analytics focuses on analytical reasoning with visual interfaces for spatial and spatio-temporal phenomena (Andrienko et al., 2007). We note several similarities between the five-step model of learning analytics (Campbell et al., 2007) and a key theoretical framework for describing sensemaking in visual analytics (Pirolli \& Card, 2005). The sensemaking loop as proposed by Pirolli and Card proposes an iterative process in which analysts collect information, schematize it, hypothesize about its meaning, and present conclusions. The five-step model for learning analytics does not include the stage of schematization, but this activity is implied by its focus on reporting, prediction, and action.

\section{Spatial learning analytics}

Current learning management systems (LMS) can capture discussion forum activity and assessment performance, but existing learning analytics methods do not explore where learning is taking place. For example, we do not incorporate knowledge about the broad spectrum of places in which students are engaging with the course (library, coffee shop, airport, etc....), or how those places of engagement may change over time (through the course of a day, on weekends, etc ...). In a fully-online class, this could include places around the world, and in the context of a Massive Open Online Course, the number and diversity of these locations is substantial. Space-time patterns are likely to be extremely diverse, as learners engage with the course contents in different places at different times. We do not know what types of locations are commonly associated with learner engagement during the morning, versus the evening, or the impact of weekends and holidays. A key advantage of online learning is that students are empowered to interact with each other and the course content at any time, in any place, but we know surprisingly little about which times and which places students choose, and contemporary LMS and associated learning analytics tools do not yet provide insights on spatial or spatiotemporal patterns, and perhaps more importantly, we do not yet understand the potential pedagogical roles for which spatial and spatio-temporal information may be helpful for teaching and learning.

In terms of pedagogy, contemporary LMSs support a wide range of pedagogical approaches, including behaviourist, cognitivist, and constructivist methods (Hodges \& Grant, 2015). The latter mode receives a great deal of attention in LMS design, as is evidenced by the proliferation of project-based, collaborative, active, and problem-based tools. Support for behaviourist and cognitivist approaches is also well-served by contemporary LMS environments via support for various types of reinforcement and for explicitly measuring outcomes. New research is needed to identify opportunities for leveraging 
spatial learner data in behaviourist, cognitivist, and constructivist pedagogical frameworks, as all three are widely used in instructional design, and elements of each are often blended by educators to create a specific course (Ertmer \& Newby, 2013). For example, an instructor leading a large online class with several hundred students may decide to adjust collaborative group assignments by taking into account where and when particular students typically interact with the LMS. Instructors may also be able to leverage location-enabled analytical tools that help them identify subgroups of students who are performing in similar ways on tests and perhaps convene those students in a special study session at a time and place that readily fits students' observed behaviours.

The role of location information in the context of learning analytics has received little attention to date. In one of the few articles in which it has been mentioned, Becker (2013) describes location as one of the three key data types to be collected to support learning analytics: timing, location, and population. Becker claims that location in learning analytics refers to the where and how students access a learning space. In the example that follows, Becker categorizes a web forum as a relevant location associated with a prototypical online learning activity. Becker appears to leave open the possibility that a relevant learning location could be in physical or virtual space.

Others have invoked the example of location tracking via mobile devices to contextualize the rise of data capture and collection around learning management systems (Wolfgang \& Hendrik, 2012) and to highlight the potential usages of mobile learning systems (Aljohani \& Davis, 2012) to support learning in out-of-classroom locations. The presence of location data in learning systems is also acknowledged in discussions about the range of ethical and privacy challenges posed by developments in learning analytics (Pardo \& Siemens, 2014). In the geographic education literature some have begun to experiment with the spatial components associated with student behaviour in digital learning systems, such as Treves, Viterbo, and Haklay (2015) who logged and visualized the movements of students on virtual field trips to explore learning outcomes.

We are aware of one prior invocation of spatial learning analytics by (Cowling, Hillier, \& Birt, 2018). In their work, Cowling et al. explore the potential for measuring the positions of digital objects in mixed-reality environments and define spatial learning analytics around making comparisons regarding those location manipulations in immersive learning environments.

Understanding space and place in learning analytics can go well beyond basic positional tracking and comparison. For example, geographic information can also be extracted from discussion posts and assignment contents using natural language processing techniques (Robinson, 2015). In combination, it may be possible to link positional information with other forms of geographic information to provide a rich context by which educators can situate and interpret the results of more traditional forms of learning analytics.

\section{Leveraging learning data with geovisual analytics}

Our research focuses on evaluating the usability and utility of geovisual analytics as a means for extending and enhancing the state of the art in learning analytics. The origins of geovisual analytics can be found in early work to develop cartographic science and technology in support of interactive mapping, leading to the 
conceptualization of geovisualization (MacEachren, 1994). With geovisualization, digital maps are constructed to support user interaction, and their analytical aims can include exploratory visual analysis as well as more traditional types of map-driven communication (DiBiase, 1990; Gahegan, 2005). Since the mid-2000s, the field of geovisualization within cartography has extended further to include geovisual analytics, which aims to support analytical reasoning with interactive visual interfaces to spatial and spatio-temporal data (Andrienko et al., 2007; Kraak, 2008; Robinson et al., 2017). The aims of geovisual analytics go beyond geovisualization in that it seeks to expose and predict patterns, support analysis of big spatial data through tight integration with computational methods, and to provide explicit support for human reasoning processes (Robinson et al., 2017).

Recent work by cartographers in geovisual analytics has resulted in new approaches for understanding complex human mobility patterns (Andrienko \& Andrienko, 2011; Benke, Sheth, Betteridge, Pettit, \& Aurambout, 2015; Kveladze, Kraak, \& Van Elzakker, 2015), characterizing the role of location in social media streams (MacEachren et al., 2011; Morstatter, Kumar, Liu, \& Maciejewski, 2013; Pezanowski, Maceachren, Savelyev, \& Robinson, 2017), and supporting spatio-temporal analysis of political and social change (Burns \& Skupin, 2013; Nelson, Quinn, Swedberg, Chu, \& MacEachren, 2015; Peuquet, Robinson, Stehle, Hardisty, \& Luo, 2015). In addition to the development of new geovisual analytics approaches for problem solving in domains like these, a concurrent stream of GIScience research has focused on evaluating the utility and usability of such approaches, with the aim of developing new guidelines for designing effective systems (Coltekin, Pettit, \& Wu, 2015; Griffin \& Bell, 2009; Roth et al., 2017). To date there have been few examples in the geovisual analytics literature that focus on the educational context, perhaps because LMS-derived learner engagement data has just begun to emerge as a viable data source for analysis. We target this particular gap with the work we present here.

\section{MapSieve: a prototype spatial learning analytics system}

To explore the potential utility of spatial dimensions in learner data, we designed and implemented a geovisual analytics system we call MapSieve to ingest, process, and visualize spatially-referenced learner data from a Cartography MOOC taught on the Coursera platform (Robinson et al., 2015).

In a typical demographic analysis use case with exploratory geovisualization tools, an analyst will cross-filter multiple displays in order to identify and probe spatial patterns. While this approach can help support inductive and abductive reasoning on spatial data (Gahegan, 2005), it relies on the analyst to make choices about which combinations to explore, and we know in advance that there are usually far too many potential combinations for any one analyst to evaluate on their own. The science of spatial analysis and geocomputation has developed a wide range of approaches to help solve this problem, and indeed, many contemporary geovisual analytics systems couple computational approaches to data reduction and clustering with interactive visual interfaces to explore and reason about the resulting patterns.

MapSieve is designed to support coordinated-multiple view geovisualization and is coupled with a brute-force computational technique intended to help users quickly 
uncover and explore multivariate facet combinations in learner data that exhibit spatial clustering. In the sections that follow we explain the design of our computational method for spatially-enhanced faceted search as well as the views included in the MapSieve interface.

\section{Spatially-enhanced multivariate facet analysis}

The use of faceted search is quite common in contemporary commercial websites from which users are expected to winnow a huge range of possibilities down to a few in order to make purchasing decisions. Faceted search supports these tasks by allowing users to leverage categorical information about items to select combinations of categories that fit their desires (Hearst et al., 2002). For example, faceted search can allow a user to search an online travel site for Hotels + Rating Above 4 Stars + Has Swimming Pool + Offers Free WiFi + Costs $<\$ 100$ Nightly to find a specific place to stay. Faceted search is also commonly found in visual analytics systems and has received substantial attention in prior visualization and human-computer interaction research (Clarkson, Desai, \& Foley, 2009; Lee, Smith, Robertson, Czerwinski, \& Tan, 2009; Smith et al., 2006).

In most cases, the faceted search technique requires that the data in question feature a hierarchical categorization. However, multivariate analysis is also possible, where facets may not necessarily be independent from one another (Ben-Yitzhak et al., 2008) and may be coupled to parametric search techniques (Tunkelang, 2009). In previous research the multivariate faceted search technique has been demonstrated to analyse images (Yee, Swearingen, Li, \& Hearst, 2003) and videos (Matejka, Grossman, \& Fitzmaurice, 2014), as well as spatiotemporal and attribute data in social media (Pezanowski et al., 2017).

We implement multivariate faceted search in MapSieve using a computational technique developed and tested in previous research. Our spatially-enhanced multivariate facet analysis method combines faceted search with a brute force computational approach that searches for facet combinations that include spatial hotspots (Robinson \& Quinn, 2018). This approach allows users to avoid dead-end search paths (which can be common in multivariate facets due to the correlation of attributes to each other) and highlights the combinations for which a potentially interesting spatial pattern may be present. In previous research we introduced the design of this method and explored its potential usefulness through case studies. In this article we evaluate its role as part of a larger interactive geovisual analytics system and provide evidence from user evaluation research regarding its potential utility and usability for supporting spatial learning analytics.

\section{Study data}

The data we explore in this study are comprised of multiple variables collected from recorded student activity in a MOOC taught in 2013 on the Coursera platform (Robinson et al., 2015). We spatially-referenced student activity data by geocoding each student using the Internet Protocol (IP) address associated with their MOOC enrolment record. Geocoding utilized the commercial MaxMind, Inc. service for locating IP addresses. Out of 49,392 students enrolled in the class, 35,783 were successfully assigned a location. 
Students were then aggregated into 2-degree wide hexbins. The Coursera platform logs student activities of various types, including forum posts, demographic survey data, assignment activity, and assessment results. These data are stored across multiple SQL tables that we joined together to make further analysis possible. In this study we focus on five types of learning data, (1) final grade earned, (2) the number of course page views, (3) the number of course forum posts, (4) the number of quiz attempts, and (5) the number of video lecture plays. Together, these learning activity data help describe key elements of student engagement in a MOOC. Even with a relatively small set of variables like this, a very large number of potential cross-filter combinations are possible, making it a good candidate for an initial case study in applying geovisualization to learning analytics.

\section{Geovisualization in MapSieve}

The MapSieve prototype system we have developed uses a coordinated set of visualization components. It includes dynamic query sliders, a thematic map of the world showing the number of students counted in hexbins for each query, a table view with summary information about demographic characteristics, and a facet combination browser that provides a visual overview of facet combinations and allows users to select a combination to explore (Figure 1). These views work in combination with each other via cross-filtering. Users may also select regions on the map to view detailed data for a subset of the hexbins on the map.

The technology driving MapSieve includes a web client built using a combination of OpenLayers (https://openlayers.org/) and JQuery (https://jquery.com/). The client integrates with a basemap service built using GeoServer (http://geoserver.org/) and a PostGIS (https://postgis.net/) extended PostgreSQL (https://www.postgresql.org/) database containing the raw data tables that originated from the Coursera MOOC LMS.

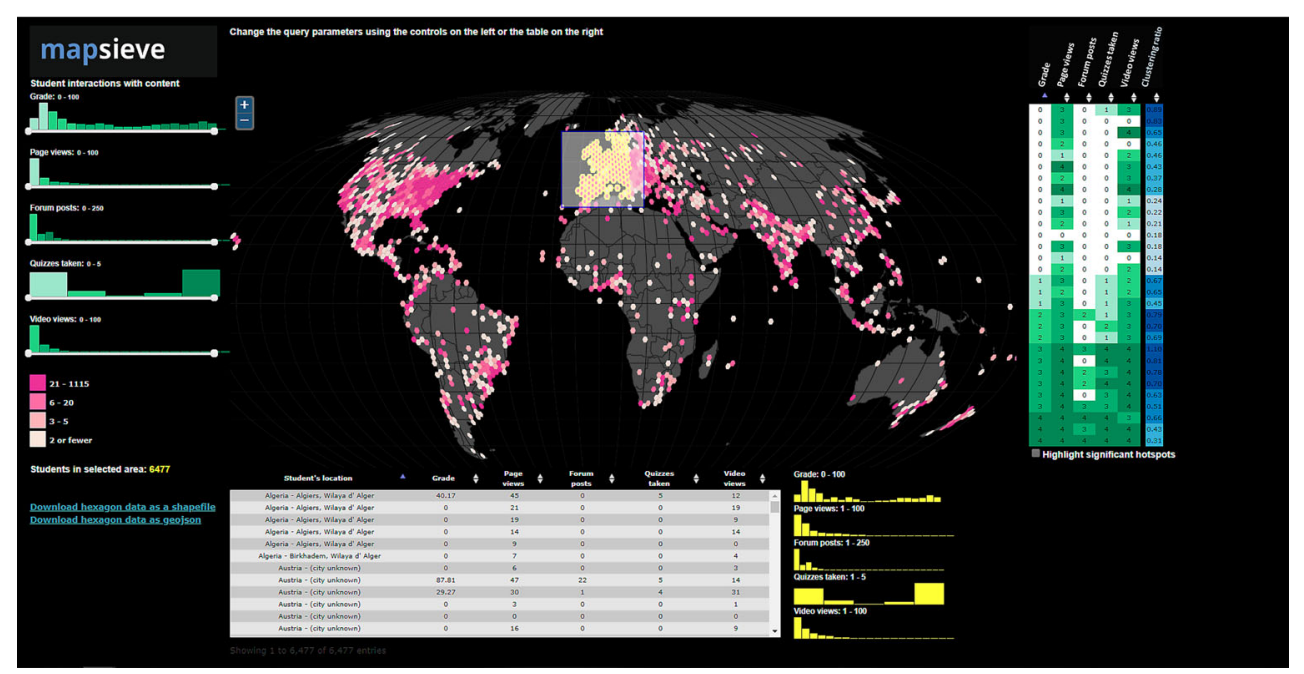

Figure 1. The MapSieve interface features multiple coordinated views to support interactive analysis of spatial learner data. 


\section{Utility and usability evaluation}

\section{Methodology}

To evaluate the utility and usability of MapSieve to support spatial learning analytics we designed an experiment that included task analysis and survey components. The study was designed to first ask users to complete prototypical spatial learning analytics tasks before asking participants to reflect on their experiences and characterize MapSieve's utility and usability. Two major tasks were developed. Task 1 asked users to explore facet combinations that we had previously identified as having interesting spatial patterns. Users were prompted to use the faceted query tool to select these patterns and then answer questions about student engagement and their hypotheses for what might explain the geographic patterns that emerge. Task 2 asked participants to attempt to develop at least three new insights on their own and to document which facet combination they believed best describes each pattern. Following these tasks, open-ended questions prompted participants to characterize the potential utility of MapSieve for instruction, informing the design of online courses, and for conducting institutional assessment in a university.

The task analysis portion of this study was followed by five-point Likert scale rating questions focused on usability and utility metrics for MapSieve. Usability metrics were implemented based on the System Usability Scale (Brooke, 1996) and utility metrics were developed by the authors to probe the ways in which MapSieve provides support for understanding student engagement, spatial patterns in learner data, its ability for supporting analytical reports, and its ability for prompting/testing hypotheses about spatial patterns in learner engagement. The complete test instrument with all task information and survey question details is provided in Appendix A. In addition, an orientation guide was provided to all participants to complete before the start of the experiment in order to explain the basic features of MapSieve (Appendix B).

\section{Participants}

A total of twenty-four participants were recruited to take part in this study. We recruited participants using email lists targeting instructional design, online teaching faculty, and geography user groups at our university. Our intention was to gain perspectives from both geographers as well as education experts on the potential utility and usability of the MapSieve prototype. A twenty-dollar compensation was provided to encourage participation in this experiment. The demographic profile of our resulting participant pool is shown in Figure 2.

\section{Usability evaluation results}

Survey responses on Usability Metrics for MapSieve help contextualize its relative strengths and weaknesses in terms of its user experience (Figure 3). Users agreed more often than not that they could use MapSieve without technical support from another person, that its interface was consistent, that people could learn to use it quickly, and that it is simple. The usability results then begin to trend to a more neutral or negative stance when it comes to its overall integration, the confidence users have in working with the tool, and its general ease of use. We note that no users chose the most negative 
Gender

Age Profile

\begin{tabular}{|cc|}
\hline Male & Female \\
\hline 11 & 13 \\
\hline
\end{tabular}

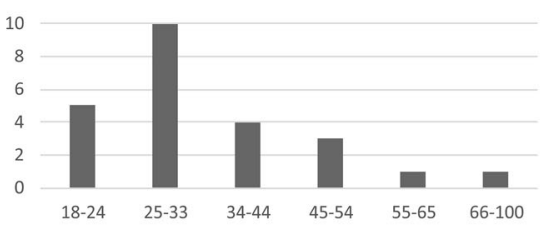

Responses to "I Consider Myself Knowledgeable In These Topics:"

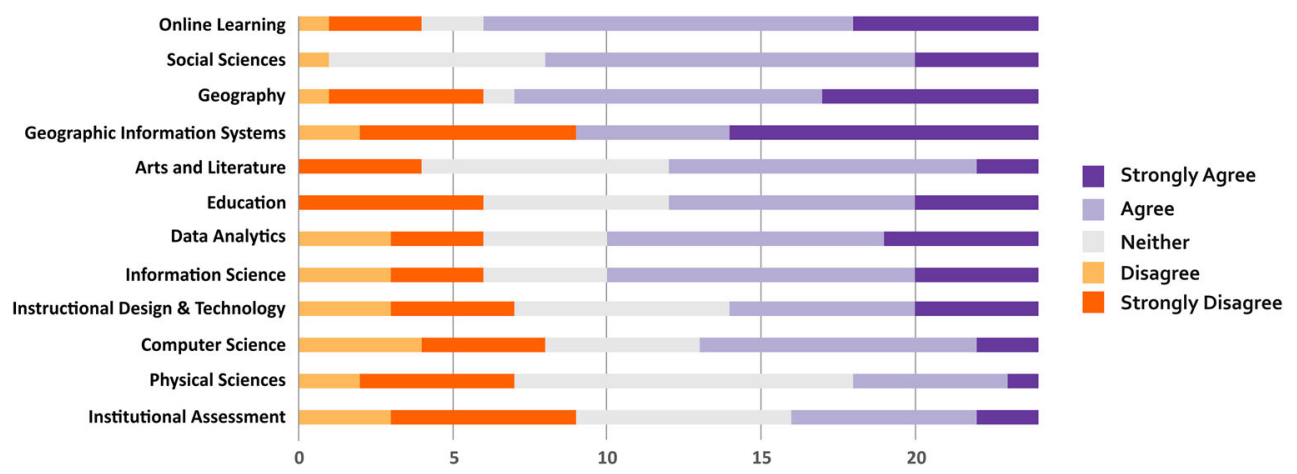

Figure 2. A visual summary of the demographic characteristics of participants in our study of the MapSieve prototype.

possible rating for any of these usability metrics. The usability results suggest that we should focus on improving the integration of MapSieve's different pieces, provide additional explanatory guidance in the interface to improve user confidence in what they're seeing, and to focus on interface improvements that will make it more likely that users can work with the system without receiving training.

\section{Utility evaluation results}

The results from survey questions on aspects of MapSieve's utility offer insights on its potential to solve problems in spatial learning analytics. Each metric garnered an average rating of 'Agree' on our rating scale, and little variation is found between the top and lowest ranked utility metrics (Figure 4). However, we note that the most strongly supported metric was that MapSieve would be helpful when generating analytical reports
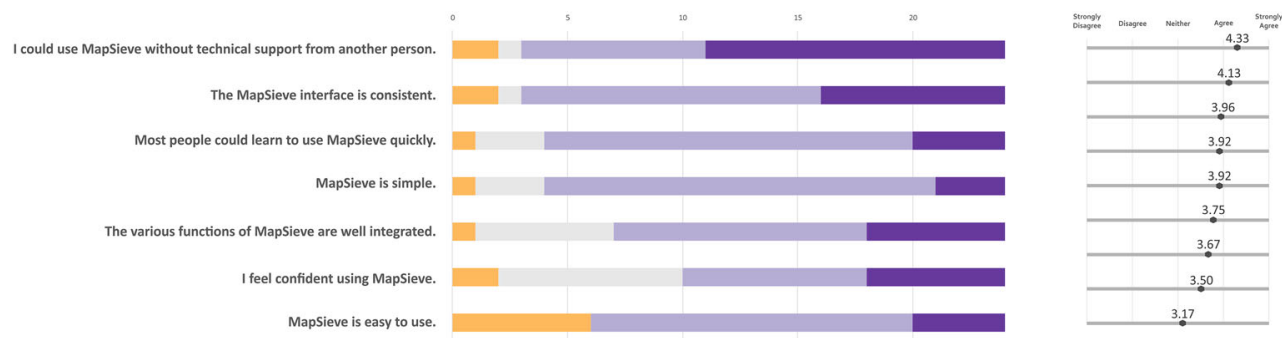

Figure 3. A summary of MapSieve usability ratings from our user study. 

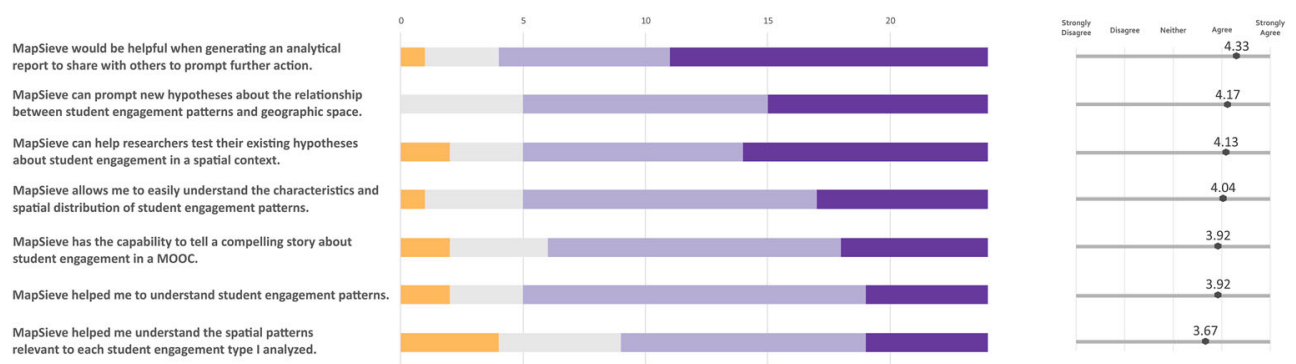

Figure 4. A summary of MapSieve utility ratings from our user study.

to share with others, and the least supported metric was that it would help users understand the spatial patterns relevant to types of student engagement. As in our usability assessment, no ratings indicating strong disagreement were associated with any of the utility metrics. These results indicate that MapSieve is scoring reasonably well on key utility metrics, and in comparison with the usability ratings, it looks as though interface usability rather than utility deserves greater attention in future MapSieve development.

\section{Qualitative evaluation feedback}

Participants provided text responses to task analysis prompts and questions about the current and potential future utility of MapSieve. Additionally, we provided the opportunity for users to tell us anything else on their minds after the conclusion of the study. Based on these text responses, the following sections highlight areas of improvement we can make to MapSieve in terms of its interface and analytical support, as well as the ways in which users see the potential for MapSieve to support key spatial learning analytics goals to understand engagement, improve pedagogy, and support institutional assessment. An anonymized subset of the raw survey data table is provided in Appendix $C$ which includes all of the open-ended text responses from our participants. In the interest of concision, we summarize the key themes here regarding interface improvements and analytical improvements, and representative quotes are provided in the subsection describing participant feedback on potential use cases for spatial learning analytics.

\section{Interface improvements}

Open-ended feedback from users indicated several areas for potential MapSieve interface improvements. For example, users highlighted the need for MapSieve to update the display in real-time as faceted queries are constructed, rather than having to click a button to run each query. Several users also noted having trouble with basic panning and zooming on the hexbin map, where both interactions behaved inconsistently compared to their experiences with other web maps. Others suggested that we should add the ability to click and set specific value thresholds for the faceted search parameters to support more fine-grained questions.

\section{Analytical improvements}

Suggested analytical improvements to MapSieve included the need to support temporal as well as spatial multivariate analysis. For example, to explore the extent to which student 
engagement may be changing over time, and whether or not there is a potential spatial signal associated with that change. Several participants indicated a desire to have more contextual data to help them understand and explain patterns. For example, to include descriptive population statistics, educational attainment information, language data, and other types of attributes that could help explain the patterns seen in MapSieve. A related request was to include basic descriptive statistics for learner variables. Finally, multiple users expressed a desire to compare multiple faceted query results, suggesting that a small-multiple map design may be a good option to consider in conjunction with the facet combination approach we have implemented in MapSieve.

Participants provided a great deal of feedback through open-ended responses to prompts we gave them to explore specific facet combinations. Their complete responses are available in Appendix $C$ and we summarize the results here for the sake of brevity. These results confirmed that users were able to detect and explain the patterns we had explicitly prompted them to explore. When we asked users to explore on their own and then suggest interesting facet combinations and associated hypotheses, the results were more mixed, with about half of the users providing a facet combination number they found noteworthy, and a higher proportion providing a question or hypothesis associated with the learner data without any listed facet combination. This suggests that while MapSieve may be prompting the kind of analytical engagement we had hoped for, that the spatial facet combination technique is not necessarily working as intended for all of our users. In open-ended comments a few users suggested that they wanted to compare multiple facet combinations more directly - echoing comments provided in other areas of our survey where we asked users to suggest improvements to MapSieve more generally.

\section{Envisioning support for spatial learning analytics}

Several of our survey questions asked participants to reflect on potential use cases for MapSieve and to suggest areas in which we could improve its utility. In terms of using MapSieve to better understand student engagement in a course, many participants suggested that it could help them see different educational outcomes related to language and cultural factors. As one participant described, ' ... it would help in identifying where students have a particular pattern of engagement, and adjust accordingly for that audience (like changing the requirements for forum posts to make them more accessible).' One participant was less hopeful, however, stating,

I might notice general differences in how different cultures engage with the materials, but l'd need help thinking about what to do with that. It might be more helpful when aggregated to the level of a curriculum or a program, rather than an individual course.

We also asked participants to envision a way in which a tool like MapSieve could be used to improve the design of a course. Participant responses to this prompt tended to focus on how this type of system could help them create interventions to target specific regional subgroups in a MOOC. For example, one response said, 'I would think MapSieve could help designers create forms of assessment that could be adapted for culture, language and interest.' Another said, 'It could potentially be used to better direct student and support resources based on each specific class.' One participant suggested an inversion of our assumed use case, and said, 'One way for it to help build a better online course is to give students advice before they actually start the course according to the student's location and past grades.' 
Finally, we asked participants to think about using a tool like MapSieve from the perspective of an institutional analyst. Participants suggested that institutions could use spatial learning analytics to help direct recruiting efforts, to provide improved advising support for students from around the world, and to provide reporting to faculty based on institution-wide data to suggest pedagogical interventions. For example, one participant stated that spatial learning analytics could, 'Help(ing) students and faculty predict what kinds of engagement will promote a higher grade (and hopefully learning).' Another participant thought it would help, '... narrow down target countries or regions to advertise their online courses / program(s) to attract more students.' One person suggested that it would be a useful framework for supporting study groups; 'It may be interesting, given the oft believed idea that learning occurs best in groups, to see if students in areas with other students could meet up to do coursework.'

\section{Discussion and limitations}

Our research to design and evaluate a prototype geovisualization for supporting spatial learning analytics has shown that educators and geographers are capable of using such a system with minimal training, that relatively simple interactive tools can support basic spatial learning analytics tasks, and that there are a variety of interesting future directions in which we should experiment with spatial learning analytics to understand learner behaviour, improve teaching, and support institutional assessment. Along the way we have also identified a variety of specific usability and utility improvements that can be made to the MapSieve tool and to consider when developing future geovisualization environments for spatial learning analytics.

While the use of spatially-enabled query facets was something we explicitly prompted in multiple tasks and survey questions, it did not feature prominently in participant responses in questions where we did not ask about it directly. We do not assume this means the method is therefore already ideally-designed, but rather that it supported the tasks we prompted participants to complete, and that it did not pose significant usability issues above and beyond the rest of the MapSieve interface. One of the few direct comments on the technique outside of questions where we specifically asked them to talk about query facets suggested that we need to make it easy to compare multiple facet combinations. What we have learned from this aspect of our study is that we need to further evaluate its usefulness by comparing what people find with facet combinations versus what those may find in a version of MapSieve that does not include this feature.

Overall usability ratings were generally good for MapSieve, and no participants found the need to provide a strong negative rating for any of the usability heuristics. However, we note the need to focus on improving the coordination between MapSieve elements, fixing bugs associated with panning and zooming the map, and in making small visual refinements to the user interface to improve legibility and aesthetic qualities. Users also asked us to make it possible for query combinations to generate results in real time to obviate the need to click a button to run a query.

Utility ratings for the MapSieve prototype were also generally positive, once again with no responses indicating a strong negative rating on any of our utility metrics. While there was not a great deal of noteworthy difference between the best supported and least supported utility metric, we note that the metrics on exploratory utility earned slightly higher 
ratings overall as compared to the metrics we used to explanatory utility. Users want to know more about what constitutes student engagement, and they also want to drill down further into the spatial patterns that may emerge from learner engagement data. In open-ended feedback at the end of our survey, one user expressed a desire to better understand the spatial cluster detection element of our query facet tool. Another user expressed a desire to integrate time into the MapSieve framework to understand the dynamism in patterns of engagement.

In this research we acknowledge the limitation associated with the fact that we have chosen a single course context in which to evaluate a spatial learning analytics approach. We were also limited in terms of the usable geographical scale for which location data existed for our case study. It would be possible with higher precision geocoding and a greater density of students in smaller areas to explore patterns below the regional level (for example, if we were exploring data from a single college campus rather than a course taught to people around the world), but we were not able to accomplish that with this project.

\section{Conclusions and future research}

In this work we have described the design and evaluation of a prototype spatial learning analytics geovisualization. The MapSieve application couples a computational approach using spatially-enabled query facets to an interactive map and to support guided exploration in learner data. Our evaluation results suggest that the prototype system we created scores well in terms of its overall usability and utility in support of spatial learning analytics. Our study participants provided guidance through their rating responses and open-ended responses regarding multiple ways in which we can improve the usability and utility of MapSieve and have suggested areas to focus on in the future to improve support for spatial learning analytics more generally. Few spatial learning analytics systems have been described in the literature, and we are not aware of similar work that has evaluated this type of geovisualization with educators and geographers. Our progress here advances what we know about supporting one aspect of the previously proposed spatially-enabled smart campus (Skupin, 2013), showing how spatial data science may be applied to learner data itself to improve teaching, course design, and institutional assessment. It also illuminates the potential to leverage data from open geospatial education (Belgiu, Strobl, \& Wallentin, 2015) in order to improve learning outcomes.

In future work we wish to address the challenges our study participants raised regarding the need for a spatial learning analytics system to explicitly incorporate time. A wide range of factors may play into the decision for a learner to engage with an online course at a given time of the day, including work considerations and access to the internet. If we were to continue using the query facet approach we have adopted here for MapSieve, we would need to further extend that method to handle and represent spatiotemporal data. We hypothesize that in addition to linear representations of time, that including configurable calendar views would also be quite useful, as we can reasonably expect that patterns will be present in daytime activity vs. night activity, as well as between work days and the weekend.

Many of our users also reported a desire to see additional demographic data along with the ability to explore it across multiple spatial scales. In our work here we used data from a 
single $\mathrm{MOOC}$, aggregated to a single hexagonal grid. In future research we will need to address the challenges associated with comparing multiple courses, analysing traditional online classes that have much smaller student populations than MOOCs, fusing together learner data with a deeper set of demographic variables, and supporting geovisualization across a range of user-configurable spatial scales. Developing and evaluating new cartographic representations to support analysing big spatial data in other contexts will likely translate into the spatial learner analytics context as well.

One of our study participants encouraged us to think about the use of spatial learning analytics from the student perspective. We know very little about what students themselves expect to leverage in terms of geographic information in personalized learning systems that are driven by learning analytics approaches. How can students be made aware of classmate presence in an LMS? It is often hard for online students to feel the presence of their classmates in quite the same way as it is experienced in a classroom or lab setting, and we believe there are ways to leverage spatial information about LMS interaction that may help students achieve this feeling at a distance. We also need to know how can we help students form ad hoc groups to study and collaborate together at a distance. Furthermore, it is possible that self-awareness of patterns highlighting where/when they are engaging with an LMS may be helpful to students. Finally, we need to engage students, faculty, and administrators in frank discussions on managing the spatial dimensions of privacy associated with the expansion of learning analytics methods and systems. One idea we would like to explore is to aggregate campus location data from an LMS into types of locations, and explore a generalized map of those location types. For example, all events taking place in a library, dorm, classroom, or laboratory could be categorized as such and visualized as part of a location category, rather than emphasizing an explicit location reference that would exacerbate location privacy issues. Understanding what types of learner engagement happen at library locations versus laboratory settings could be quite useful to educators and institutional analysts and eschew the need to focus on the exact locations of individuals. Therefore, we suggest that the spatial dimension of spatial learning analytics need not be explicit coordinates.

At the institutional level, analysts are expected to report on key metrics for course completion, engagement, progress toward degree milestones, and many other aspects of learner activity. Such metrics are often driven by strategic planning goals and accreditation concerns. How might institutional analysts leverage geographic information to better understand adult learners in online programmes who may be participating around the world? At the institutional level, knowing which places on campus are attracting lots of interaction with the campus LMS at specific times may improve the provisioning of student support services or scheduling useful open hours for a library. We need to evaluate the potential utility of geospatial information more broadly in the context of learning analytics, as contemporary learning analytics approaches do not routinely consider geographic context.

As we reflect on the results of our initial study on the potential of spatial learning analytics, we see the need for a new research trajectory that brings together cartographers, geographers, and educators to identify key opportunities for extracting and visualizing geographic insights in the context of learning analytics, design and develop prototype spatial learning analytics systems for analysing learner activity, and to evaluate these systems with the appropriate stakeholders. 


\section{Acknowledgements}

We wish to thank Scott Pezanowski at the GeoVISTA Center for providing technical assistance to support the implementation of the MapSieve prototype.

\section{Disclosure statement}

No potential conflict of interest was reported by the author(s).

\section{Funding}

This work was supported in part by a Research Initiation Grant from the Center for Online Innovation in Learning at Penn State University.

\section{Notes on contributors}

Dr. Anthony C. Robinson is Associate Professor, Director for Online Geospatial Education programmes and Assistant Director for the GeoVISTA research centre in the Department of Geography at Penn State University. Dr Robinson's research focuses on the science of interface and interaction design for geographic visualization. He currently serves as the Co-Chair of the Commission on Visual Analytics for the International Cartographic Association.

Cary L. Anderson, M.S. Cary is a doctoral candidate in Marketing in the Joseph M. Katz Graduate School of Business at the University of Pittsburgh. Her research focuses on the influence of seemingly-incidental design factors in maps and other visual graphics on user cognition, emotion, and behaviour.

Dr. Sterling D. Quinn is Assistant Professor and GIS Program Director in the Department of Geography at Central Washington University. His research interests include crowdsourced geographic data, free and open source GIS, and the politics of online maps.

\section{ORCID}

Anthony C. Robinson (D) http://orcid.org/0000-0002-5249-8010

Cary L. Anderson (D) http://orcid.org/0000-0003-1702-9590

Sterling D. Quinn (I) http://orcid.org/0000-0002-4900-8885

\section{References}

Adams, P. C. (2018). Geographies of media and communication III: Academic communications and the digital communication environment. Progress in Human Geography, 43(4), 739-748. doi:10. $1177 / 0309132518763849$

Aljohani, N. R., \& Davis, H. C. (2012, October 16-18). Learning analytics in mobile and ubiquitous learning environments. Proceedings of the 11th international conference on mobile and contextual learning, MLearn 2012, Helsinki, 70-77. Retrieved from http://ceur-ws.org/Vol-955/./papers/ paper_70.pdf

Andrienko, G., Andrienko, N., Jankowski, P., Keim, D., Kraak, M. J., MacEachren, A. M., \& Wrobel, S. (2007). Geovisual analytics for spatial decision support: Setting the research agenda. International Journal of Geographical Information Science, 21(8), 839-857.

Andrienko, N., \& Andrienko, G. (2011). Spatial generalization and aggregation of massive movement data. IEEE Transactions on Visualization and Computer Graphics, 17(2), 205-219.

Becker, B. (2013). Learning analytics: Insights into the natural learning behavior of our students. Behavioral \& Social Sciences Librarian, 32(1), 63-67. doi:10.1080/01639269.2013.751804 
Belgiu, M., Strobl, J., \& Wallentin, G. (2015). Open geospatial education. ISPRS International Journal of Geo-Information, 4(2), 697-710.

Benke, K. K., Sheth, F., Betteridge, K., Pettit, C. J., \& Aurambout, J. P. (2015). Application of geovisual analytics to modelling the movements of ruminants in the rural landscape using satellite tracking data. International Journal of Digital Earth, 8(7), 579-593. doi:10.1080/17538947.2013.872703

Bennett, R., \& Kent, M. (Eds.). (2017). Massive open online courses and higher education | what went right, what went wrong and where to next? (1st ed.). Retrieved from https://www.taylorfrancis. com/books/e/9781315594248

Ben-Yitzhak, O., Golbandi, N., Har'El, N., Lempel, R., Neumann, A., Ofek-Koifman, S., ... Yogev, S. (2008). Beyond basic faceted search. Proceedings of the 2008 International Conference on Web Search and Data Mining, 33-44. doi:10.1145/1341531.1341539

Brooke, J. (1996). SUS: A "quick and dirty" usability scale. In P. W. Jordan, B. Thomas, B. A. Weerdmeester, \& A. L. McClelland (Eds.), Usability evaluation in industry (p. 252). London: Taylor and Francis.

Burns, R., \& Skupin, A. (2013). Towards qualitative geovisual analytics: A case study involving places, people, and mediated experience. Cartographica: The International Journal for Geographic Information and Geovisualization, 48(3), 157-176. doi:10.3138/carto.48.3.1691.

Campbell, J. P., DeBlois, P. B., \& Oblinger, D. G. (2007). Academic analytics: A new tool for a new era. EDUCAUSE Review, 42(4), 40-57.

Chen, Q., Chen Y., Liu, D., Shi, C., Wu, Y., \& Qu, H. (2015). PeakVizor: Visual analytics of peaks in video clickstreams from massive open online courses. IEEE Transactions on Visualization and Computer Graphics, 99, 1-1. doi:10.1109/TVCG.2015.2505305

Clarkson, E., Desai, K., \& Foley, J. (2009). Resultmaps: Visualization for search interfaces. IEEE Transactions on Visualization and Computer Graphics, 15(6), 1057-1064. doi:10.1109/TVCG.2009.176

Coltekin, A., Pettit, C., \& Wu, B. (2015). Geovisual analytics: Human factors. International Journal of Digital Earth, 8(8), 595-598. doi:10.1080/17538947.2015.1047173

Cowling, M. A., Hillier, M., \& Birt, J. R. (2018). Integrating mixed reality spatial learning analytics into secure electronic exams. ASCILITE 2018 conference proceedings - open oceans: Learning without borders, 330-334. Retrieved from https://research.bond.edu.au/en/publications/integratingmixed-reality-spatial-learning-analytics-into-secure-

DiBiase, D. (1990). Visualization in the earth sciences. Earth and Mineral Sciences, Bulletin of the College of Earth and Mineral Sciences, The Pennsylvania State University, 59(2), 13-18.

Ertmer, P. A., \& Newby, T. J. (2013). Behaviorism, cognitivism, constructivism: Comparing critical features from an instructional design perspective. Performance Improvement Quarterly, 26(2), 43-71. doi:10.1002/piq.21143

Gahegan, M. (2005). Beyond tools: Visual support for the entire process of GIScience. In J. Dykes, A. M. MacEachren, \& M. J. Kraak (Eds.), Exploring geovisualization (pp. 83-99). London: Elsevier.

Griffin, A. L., \& Bell, S. (2009). Applications of signal detection theory to geographic information science. Cartographica: The International Journal for Geographic Information and Geovisualization, 44(3), 145-158. doi:10.3138/carto.44.3.145

Hearst, M., Elliott, A., English, J., Sinha, R., Swearingen, K., \& Yee, K.-P. (2002). Finding the flow in web site search. Communications of the ACM, 45(9), 42-49. doi:10.1145/567498.567525

Hodges, C., \& Grant, M. (2015). Theories to support you: Purposeful use of learning management system features. Berlin: Association for the Advancement of Computing in Education, 481-486.

Janelle, D., Kuhn, W., Gould, M., \& Lovegreen, M. (2014). Advancing the spatially enabled smart campus: Specialist meeting final report (Report). Santa Barbara: Center for Spatial Studies, University of California.

Kraak, M.-J. (2008). Editorial: From geovisualisation toward geovisual analytics. The Cartographic Journal, 45(3), 163-164. doi:10.1179/174327708X315183

Kveladze, I., Kraak, M.-J., \& Van Elzakker, C. P. J. M. (2015). The space-time cube as part of a GeoVisual analytics environment to support the understanding of movement data. International Journal of Geographical Information Science, 29(11), 2001-2016. doi:10.1080/13658816.2015.1058386

Lee, B., Smith, G., Robertson, G. G., Czerwinski, M., \& Tan, D. S. (2009). Facetlens: Exposing trends and relationships to support sensemaking within faceted datasets. Proceedings of the SIGCHI Conference on Human Factors in Computing Systems, 1293-1302. doi:10.1145/1518701.1518896 
MacEachren, A. M. (1994). Visualization in modern cartography: Setting the agenda. In A. M. MacEachren \& D. R. F. Taylor (Eds.), Visualization in modern cartography (pp. 1-12). Retrieved from https://www.sciencedirect.com/bookseries/modern-cartography-series/vol/2/suppl/C

MacEachren, A. M., Jaiswal, A., Robinson, A. C., Pezanowski, S., Savelyev, A., Mitra, P., ... Blanford, J. (2011). SensePlace2: Geotwitter Analytics Support for Situation Awareness. IEEE conference on visual analytics science and technology.

Matejka, J., Grossman, T., \& Fitzmaurice, G. (2014). Video lens: Rapid playback and exploration of large video collections and associated metadata. Proceedings of the 27th Annual ACM Symposium on User Interface Software and Technology, 541-550. doi:10.1145/2642918.2647366

Morstatter, F., Kumar, S., Liu, H., \& Maciejewski, R. (2013). Understanding Twitter data with TweetXplorer. Proceedings of the 19th ACM SIGKDD International Conference on Knowledge Discovery and Data Mining, 1482-1485. doi:10.1145/2487575.2487703

Nelson, J., Quinn, S., Swedberg, B., Chu, W., \& MacEachren, A. (2015). Geovisual analytics approach to exploring public political discourse on Twitter. ISPRS International Journal of Geo-Information, 4(1), 337-366.

Pardo, A., \& Siemens, G. (2014). Ethical and privacy principles for learning analytics. British Journal of Educational Technology, 45(3), 438-450. doi:10.1111/bjet.12152

Peuquet, D. J., Robinson, A. C., Stehle, S., Hardisty, F. A., \& Luo, W. (2015). A method for discovery and analysis of temporal patterns in complex event data. International Jounal of Geographical Information Science, 29(9), 1588-1611.

Pezanowski, S., Maceachren, A. M., Savelyev, A., \& Robinson, A. C. (2017). Senseplace3: A geovisual framework to analyze place-time-attribute information in social media. Cartography and Geographic Information Science, 44. doi:10.1080/15230406.2017.1370391

Pirolli, P., \& Card, S. (2005). The sensemaking process and leverage points for analyst technology as identified through cognitive task analysis. International conference on intelligence analysis. Presented at the McLean, VA.

Robinson, A. C. (2015). Exploring class discussions from a massive open online course (MOOC) on cartography. In J. Brus, A. Vondrakova, \& V. Vozenilek (Eds.), Modern trends in cartography: Selected papers of CARTOCON 2014 (pp. 173-182). doi:10.1007/978-3-319-07926-4_14

Robinson, A. C., Demšar, U., Moore, A. B., Buckley, A., Jiang, B., Field, K., ... Sluter, C. R. (2017). Geospatial big data and cartography: Research challenges and opportunities for making maps that matter. International Journal of Cartography, 1-29. doi:10.1080/23729333.2016.1278151

Robinson, A. C., Kerski, J., Long, E. C., Luo, H., DiBiase, D., \& Lee, A. (2015). Maps and the geospatial revolution: Teaching a massive open online course (MOOC) in geography. Journal of Geography in Higher Education, 39(1), 65-82. doi:10.1080/03098265.2014.996850

Robinson, A. C., \& Quinn, S. D. (2018). A brute force method for spatially-enhanced multivariate facet analysis. Computers, Environment and Urban Systems, 69, 28-38. doi:10.1016/j.compenvurbsys. 2017.12.003

Romero, C., \& Ventura, S. (2007). Educational data mining: A survey from 1995 to 2005. Expert Systems with Applications, 33(1), 135-146. doi:10.1016/j.eswa.2006.04.005

Roth, R. E., Çöltekin, A., Delazari, L., Filho, H. F., Griffin, A., Hall, A., ... van Elzakker, C. P. J. M. (2017). User studies in cartography: Opportunities for empirical research on interactive maps and visualizations. International Journal of Cartography, 3(Suppl. 1), 61-89. doi:10.1080/23729333.2017.1288534

Shum, S. B., \& Ferguson, R. (2012). Social learning analytics. Educational Technology \& Society, 15(3), 3-26.

Siemens, G., \& Baker, R. S. J. d. (2012). Learning analytics and educational data mining: Towards communication and collaboration. Proceedings of the 2nd International Conference on Learning Analytics and Knowledge, 252-254. doi:10.1145/2330601.2330661

Skupin, A. (2013). Spatially enabled smart campus. Center for Spatial Studies Specialist Meeting, 1-3. Santa Barbara, CA.

Smith, G., Czerwinski, M., Meyers, B., Robbins, D., Robertson, G., \& Tan, D. S. (2006). Facetmap: A scalable search and browse visualization. IEEE Transactions on Visualization and Computer Graphics, 12 (5), 797-804. doi:10.1109/TVCG.2006.142

Thomas, J. J., \& Cook, K. A. (2005). Illuminating the path. New York: IEEE Press. 
Treves, R., Viterbo, P., \& Haklay, M. (2015). Footprints in the sky: Using student track logs from a "bird's eye view" virtual field trip to enhance learning. Journal of Geography in Higher Education, 39(1), 97110. doi:10.1080/03098265.2014.1003798

Tunkelang, D. (2009). Faceted search. Synthesis Lectures on Information Concepts, Retrieval, and Services, 1(1), 1-80. doi:10.2200/S00190ED1V01Y200904ICR005

United States Department of Education. (2014). Integrated Postsecondary Education Data System (IPEDS), Spring 2013 and Spring 2014, Enrollment component. Retrieved from https://nces.ed. gov/programs/digest/d14/tables/dt14_311.15.asp

Wolfgang, G., \& Hendrik, D. (2012). Translating learning into numbers: A generic framework for learning analytics. Journal of Educational Technology \& Society, 15(3), 42-57.

Wu, T., Yao, Y., Duan, Y., Fan, X., \& Qu, H. (2016). Networkseer: Visual analysis for social network in MOOCs. 2016 IEEE Pacific Visualization Symposium (PacificVis), 194-198. doi:10.1109/PACIFICVIS. 2016.7465269

Yee, K.-P., Swearingen, K., Li, K., \& Hearst, M. (2003). Faceted metadata for image search and browsing. Proceedings of the SIGCHI Conference on Human Factors in Computing Systems, 401-408. doi:10. $1145 / 642611.642681$ 